\title{
Subclinical hypothyroidism: to treat or not to treat, that is the question! A systematic review with meta-analysis on lipid profile
}

\author{
Isabel M Abreu1, Eva Lau 1,2,3, Bernardo de Sousa Pinto ${ }^{1}$ and Davide Carvalho ${ }^{1,2,3}$ \\ ${ }^{1}$ Faculty of Medicine, University of Porto, Alameda Professor Hernâni Monteiro, Porto, Portugal \\ ${ }^{2}$ Department of Endocrinology, Diabetes and Metabolism, Centro Hospitalar S. João, Alameda \\ Professor Hernâni Monteiro, Porto, Portugal \\ ${ }^{3}$ Instituto de Investigação e Inovação em Saúde, Universidade do Porto, Porto, Portugal
}

Correspondence

should be addressed

to I M Abreu

Email

isabelmrabreu1992@gmail.

com

\begin{abstract}
Previous studies suggested that subclinical hypothyroidism has a detrimental effect on cardiovascular risk factors, and that its effective treatment may have a beneficial impact on overall health. The main purpose of this review and meta-analysis was to assess whether subclinical hypothyroidism treatment is of clinical relevance, based on cardiovascular risk parameters correction. A systemic research of the literature using MEDLINE tool was performed to identify the relevant studies. Only placebo-controlled randomized control trials were included. A quantitative analysis was also performed. This systematic review and meta-analysis of randomized placebo-controlled trials assess the different impact of levothyroxine vs placebo treatment. A significant decrease in serum thyroid-stimulating hormone and total and low-density lipoprotein cholesterol was obtained with levothyroxine therapy $(66,9$ and $14 \%$, respectively) and, although modest, this could be significant in terms of reduction of the incidence of coronary artery disease. Other significant results of lipid parameters were not obtained. This systematic review provides a strong evidence-based data in favour of specific changes and beneficial effects of levothyroxine treatment.
\end{abstract}
Key Words
- subclinical
- hypothyroidism
treatment
- lipids

\section{Introduction}

Subclinical hypothyroidism (SCH) is diagnosed biochemically when both serum-free thyroxine (FT4) and free triiodothyronine (FT3) are within the normal range, whereas the serum thyroid-stimulating hormone (TSH) is elevated (1). Although considered an asymptomatic disorder, some patients may present non-specific symptoms, which can be suggestive of hypothyroidism $(2,3)$. The prevalence of $\mathrm{SCH}$ in the population is relatively high, and it varies from between $4 \%$ and $20 \%$. Furthermore, it depends on gender and age, usually occurring more frequently over the age of 60 , with a prevalence of around $15 \%$ and $8 \%$ for women and men, respectively.
Thyroid dysfunction has significant public health consequences. Overt thyroid disorder has been widely recognized as being a cardiovascular risk factor, as it is associated with dyslipidaemia, insulin resistance, hypertension, inflammation, oxidative stress, endothelial dysfunction, coagulation disorders and, thus, atherosclerosis $(4,5)$. Recent studies suggest that this may also be true for SCH. In fact, a growing number of studies have associated $\mathrm{SCH}$ with an increased number of cardiovascular risk factors, including hypertension (6), weight gain (7), insulin resistance (8), hypercholesterolaemia, dyslipidaemia (9), and coronary and ischaemic heart diseases $(10,11)$.

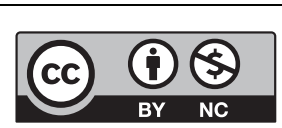

This work is licensed under a Creative Commons Attribution-NonCommercial 4.0 International License. 
As TSH screening has been shown to be cost-effective when applied to increased risk-associated subpopulations, its widespread use in primary clinical care will increase the number of patients diagnosed with SCH (12). However, management of $\mathrm{SCH}$ is still controversial, due to uncertainties related to the magnitude of its clinical benefit. On one hand, current guidelines recommend that $\mathrm{SCH}$ should be treated in specific conditions, namely: pregnancy, infertility, patients exhibiting associated symptoms or with high risk of progression to overt hypothyroidism (about 5\% per year) (13). On the other hand, some clinicians recommend that most patients with subclinical hypothyroidism should be treated, including those with a serum TSH value below 10IU/L (14).

To our knowledge, the data regarding the effect of levothyroxine treatment on lipid levels in selected patients, including apolipoproteins, originated from small studies with heterogeneous and controversial results. The aim of this study is to establish a relationship between lipid profile and levothyroxine treatment, and also to correlate the results of several studies regarding the impact of SCH treatment on overall cardiovascular risk.

\section{Materials and methods}

\section{Search strategy}

For the systematic review, a comprehensive search of the Medline database was performed up to September 8th, 2015, using the following query: (thyroid* or hypothyroid*) and subclinic* and (cardiovascular* or cardiac* or dyslipidem*) and (treat* or manage* or levothyroxine). We followed the PRISMA checklist for meta-analysis. The search was restricted to the English language, human species and randomized control trials. Potentially studies eligible for further review were selected by screening their abstracts and title. If a study was considered relevant, then the full-text version was reviewed for further assessment. The references from these papers were used to find articles missing in the initial MEDLINE search. All full-text articles were retrieved. We excluded non-original articles, narratives and systematic reviews, or studies that did not report the outcomes proposed.

\section{Eligibility criteria}

To be included in the systematic review, studies had to be randomized placebo-controlled trials of thyroid hormone replacement in adults with subclinical hypothyroidism. The studies included in the analysis and their characteristics are listed in Tables 1 and 2 .

To be included in the meta-analysis, the studies should meet the following criteria: (1) all studies had to be randomized controlled trials comparing levothyroxine with placebo; (2) SCH had to be defined as TSH $\geq 3.5 \mathrm{IU} / \mathrm{L}$ with FT4 and FT3 concentrations within the normal reference range; (3) patients must have proved stable elevated TSH levels for at least six weeks before beginning levothyroxine or placebo treatment; (4) the study must have had a prospective evaluation of the effect of levothyroxine or placebo therapy; (5) at least two measures should have been obtained: at least a basal measurement before beginning levothyroxine or placebo treatment, and one after it; (6) the minimal duration of levothyroxine/placebo treatment had to be eight weeks (the minimal period required for an effective levothyroxine treatment); (7) both genders could be included; (8) age had to be $\geq 18$ years, as the aim was to evaluate the adult population. The studies must have studied at least one of the outcomes of interest: lipid parameters such as cholesterol, triglycerides and apolipoproteins. Studies with patients who had any disease that could interfere with lipid or cardiovascular measures, hypothalamic/pituitary or other non-thyroid diseases were excluded. We also excluded studies with patients taking thyroid or other medications that could interfere with lipid, cardiovascular or thyroid measurements. The inclusion criteria are detailed in Table 2. It is important to notice that, although Monzani and coworkers (15) fulfilled all the inclusion criteria for the meta-analysis, they studied the impact of SCH treatment on cardiac parameters and not on lipid profile and, therefore, were also excluded from the meta-analysis.

\section{Data extraction}

Data from selected studies were extracted to a Microsoft Excel database for further statistical analysis. The outcomes of interest were the changes between control and levothyroxine treatment groups in serum thyroid hormones (namely TSH, FT4 and FT3) in lipids and lipoprotein concentrations (including total, highdensity lipoprotein (HDL) and low-density lipoprotein (LDL) cholesterol; triglycerides; apolipoprotein A, apolipoprotein B; and lipoprotein(a)) and their variances between baseline and end treatment concentrations. Values were converted to SI units, using the following

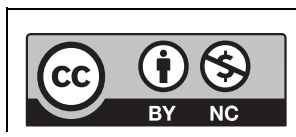

This work is licensed under a Creative Commons Attribution-NonCommercial 4.0 International License. 
Table 1 Overview of 16 studies included in qualitative analysis.

\begin{tabular}{|c|c|c|c|c|c|}
\hline \multirow[b]{3}{*}{ Study } & Sample size & Age (years)/mean & \multirow[b]{3}{*}{ Country } & \multirow{3}{*}{$\begin{array}{c}\text { TSH } \\
\text { criteria } \\
\text { for SCH } \\
\text { (IU/L) }\end{array}$} & \multirow{3}{*}{$\begin{array}{l}\text { Time of } \\
\text { study } \\
\text { (months) }\end{array}$} \\
\hline & - Placebo (M/W) & - Placebo group & & & \\
\hline & $\Delta$ L-T4 (M/W) & $\diamond$ L-T4 group & & & \\
\hline Cooper et al. (29) & $\begin{array}{l}33(1 / 32) \\
\bullet 16(1 / 15) \\
\Delta 17(0 / 17)\end{array}$ & $\begin{array}{l}32-78 / 54.0 \\
\bullet 32-71 \\
\diamond 44-78\end{array}$ & USA & $>3.5$ & 12 \\
\hline
\end{tabular}

$\begin{array}{lll}\text { Jaeschke et al. (21) } & 37(9 / 28) & >55 / 68.0 \\ & \bullet 19(3 / 16) & \bullet 68 \pm 6.4 \\ \text { Meier et al. (22) } & \diamond 18(6 / 12) & \diamond 68 \pm 9.4 \\ & 66(0 / 66) & 18-75 / 58.0 \\ & \bullet 33(0 / 33) & \bullet 57.1 \pm 1.9 \\ & \diamond 33(0 / 33) & \diamond 57.1 \pm 1.8 \\ \text { Monzani et al. (15) } & 20(2 / 18) & -/ 32.6 \\ & \bullet 10(1 / 9) & \bullet 29.2 \pm 9.4 \\ & \diamond 10(1 / 9) & \diamond 34.3 \pm 12.3\end{array}$

$\begin{array}{lll}\text { Christ-Crain et al. (33) } & 63(0 / 63) & 32-79 / 58.0 \\ & \bullet 32(0 / 32) & \bullet- \\ & \diamond 31(0 / 31) & \diamond- \\ \text { Monzani et al. (30)* } & 45(8 / 37) & <55 / 37.0 \\ & \bullet 22(-/-) & \bullet- \\ & \diamond 23(-/-) & \diamond-\end{array}$

lqbal et al. (25)

\begin{tabular}{ll} 
Iqbal et al. (25) & $64(33 / 31)$ \\
& $\bullet 32(17 / 15)$ \\
& $\diamond 32(16 / 16)$ \\
Razvi et al. (31) & $100(18 / 82)$ \\
& $\bullet 50(8 / 42)$ \\
& $\diamond 50(10 / 42)$ \\
& $26(-/-)$ \\
Teixeira et al. (27)* & $\bullet 15(-/-)$ \\
& $\diamond 11(-/-)$ \\
Teixeira et al. (28)* & $38(3 / 35)$ \\
& $\bullet 20(1 / 19)$ \\
& $\diamond 18(2 / 16)$ \\
\hline
\end{tabular}


Table 1 Continued.

\begin{tabular}{|c|c|c|c|c|c|c|c|}
\hline Study & $\frac{\frac{\text { Sample size }}{\text { - Placebo (M/W) }}}{\Delta \text { L-T4 (M/W) }}$ & $\frac{\frac{\text { Age (years)/mean }}{\text { - Placebo group }}}{\Delta \text { L-T4 group }}$ & Country & $\begin{array}{c}\text { TSH } \\
\text { criteria } \\
\text { for SCH } \\
\text { (IU/L) }\end{array}$ & $\begin{array}{c}\text { Time of } \\
\text { study } \\
\text { (months) }\end{array}$ & Outcomes & $\begin{array}{c}\text { Mean dose of } \\
\text { L-T4 replacement } \\
(\mu \mathrm{g} / \text { day })\end{array}$ \\
\hline Mikhail et al. (26) & $\begin{array}{l}120(2 / 118) \\
\bullet 60(1 / 59) \\
\diamond 60(1 / 59)\end{array}$ & $\begin{array}{l}15-60 /- \\
\bullet 31.76 \pm 9.89 \\
\diamond 32.3 \pm 10.2\end{array}$ & Kuwait & $4-10$ & 13 & TSH; TC; HDL; LDL; TG & 72.0 \\
\hline Nagasaki et al. (32)* & $\begin{array}{l}95(0 / 95) \\
\bullet 47(0 / 47) \\
\diamond 48(0 / 48)\end{array}$ & $\begin{array}{l}-l- \\
\bullet 66.0 \pm 3.0 \\
\diamond 64.2 \pm 2.59\end{array}$ & Japan & $>4.0$ & 5 & $\begin{array}{l}\text { BMI; SBP; DBP; pulse } \\
\text { pressure; pulse rate; } \\
\text { TSH; FT4; FT3; TC; } \\
\text { HDL; LDL; TG; CRP; } \\
\text { BaPWV; PET/ET ratio }\end{array}$ & 25.8 \\
\hline Martins et al. (33) & $\begin{array}{l}22(0 / 22) \\
\bullet 13(0 / 13) \\
\diamond 9(0 / 9)\end{array}$ & $\begin{array}{l}-l- \\
\bullet 44.4 \pm 8.9 \\
\diamond 51.7 \pm 10.2\end{array}$ & Brazil & $4-12$ & 12 & $\begin{array}{l}\text { Left ventricular } \\
\text { systolic and diastolic } \\
\text { function }\end{array}$ & - \\
\hline
\end{tabular}

Studies with (*) were included in meta-analysis.

ApoA, apolipoprotein A; ApoB, apolipoprotein B; BaPWV, brachial-ankle pulse wave velocity; BMI, body mass index; CO, cardiac output; DBP, diastolic blood pressure; EDD, end-diastolic diameter; ET, ejection time; FMD, brachial artery flow-mediated dilatation, an early marker of atherosclerosis; FS, fractional shortening; FT3, free triiodothyronine; FT4, free thyroxine; HDL, high-density lipoprotein; HR, heart rate; IMT, intima-media thickness; IVRT, isovolumetric relaxation time; LDL, low-density lipoprotein; Lp(a), lipoprotein(a); L-T4, levothyroxine treatment; LVM, left ventricular mass index; $\mathrm{M}$, men; MAT, mitral acceleration time; MBP, mean blood pressure; MDT, mitral deceleration time; NT-proBNP, N-terminal prohormone form of brain natriuretic peptide; Peak A, late transmitral flow velocity; Peak E, early transmitral flow velocity; PEP/LVET, pre-ejection period/left ventricular ejection time; ProANP, prohormone atrial natriuretic peptide; PWthd, diastolic posterior wall thickness; QKD interval, time between the Q wave on the electrocardiogram and the detection of the last Korotkoff sound in the antecubital fossa; SBP, systolic blood pressure; Sthd, diastolic interventricular septum thickness; SVR, systemic vascular resistance; TBG, thyroxine-binding globulin; TC, total cholesterol; TG, triglycerides; tHcy, total homocysteine; TPO-Ab+, positive thyroperoxidase antibodies; TSH, thyroid-stimulating hormone; tT3, total triiodothyronine; tT4, total thyroxine; Vit B12,

vitamin B12; W, women.

conversion factors $(16,17)$ : to convert FT4 from ng/mL to $\mathrm{pmol} / \mathrm{L}$, values were multiplied by 12.87 ; to convert FT3 from ng/dL to pmol/L, values were multiplied by 15.4; to convert total, HDL and LDL cholesterol from $\mathrm{mg} /$ $\mathrm{dL}$ to $\mathrm{mmol} / \mathrm{L}$, values were divided by 38.67 ; to convert triglycerides from $\mathrm{mg} / \mathrm{dL}$ to $\mathrm{mmol} / \mathrm{L}$, values were divided by 88.57 ; to convert apolipoproteins $\mathrm{A}$ and $\mathrm{B}$ from $\mathrm{mg} /$ $\mathrm{dL}$ to $\mathrm{g} / \mathrm{L}$, values were multiplied by 0.01 ; both values of lipoprotein(a) were already in milligrams per decilitre and were not converted.

Other data were also extracted from the selected studies: number of patients included (total, levothyroxine and placebo groups), age and gender distribution, TSH criteria for definition of $\mathrm{SCH}$ and treatment dosages. This data is shown on Table 1.

\section{Statistical analysis}

The statistical analysis was performed using Review Manager, 5.3 edition. The studies were assumed to be heterogeneous and a random model meta-analysis weighted by the inverse variance was first applied. This model assumes that variability is due to sampling error and also to the variability in the population of effects (18). The experimental group was compared to the control group by using the Raw (unstandardized) mean (c) 2017 The authors

http://www.endocrineconnections.org DOI: 10.1530/EC-17-0028 and standard deviation differences (using the most appropriate formula, taking into consideration that we are studying a pre-post score between baseline and end treatment values) (19). For continuous outcomes, pooled estimates and their 95\% confidence intervals were obtained with the random effects method (20). Heterogeneity of treatment effects was assessed for the included studies, using Cochrane's $\chi^{2}$ test, with $P<0.10$ representing evidence of heterogeneity. The degree of heterogeneity was measured by the $I^{2}$ statistic, with substantial heterogeneity indicated by $I^{2} \geq 50 \%$ (18). The total weight of each study that contributes to the analysis of each parameter is shown in Table 3.

\section{Results}

\section{Literature search}

The initial MEDLINE literature search included 366 studies, after applying the filter for human species and English language. Subsequently, 343 studies were excluded for the following reasons: (1) 117 studies were non-original or systematic reviews, (2) 181 studies were excluded by screening title and abstracts, and (3) 45 articles were excluded by adding a new filter (Randomized Controlled Trials). The remaining 23 full-text articles were 
Table 2 Revised study inclusion criteria. Cooper et al. (29)
Jaeschke et al. (21) Meier et al. (22) Monzani et al. (15) Caraccio et al. (23)* Kong et al. (24) Christ-Crain et al. (33) Monzani et al. (30)* Christ-Crain et al. (35) Iqbal et al. (25) Razvi et al. (30) Teixeira et al. (26)* Teixeira et al. (27)* Mikhail et al. (26) Nagasaki et al. (32)* Martins et al. (32) Mean (total) analysis, of which only five studies fulfilled the inclusion criteria described above, and were thus examined in a quantitative manner. The literature search process is summarized in Fig. 1.

Studies with (•) met criteria. Criteria not declared in a study were considered not done. Studies with (*) were included in the meta-analysis. 
Table 4 Mean percentage change between pre and post treatment values for each study for thyroid hormones and lipid parameters.

\begin{tabular}{|c|c|c|c|c|c|c|c|c|c|}
\hline & \multicolumn{3}{|c|}{ TSH } & \multicolumn{3}{|c|}{ Free thyroxine (FT4) } & \multicolumn{3}{|c|}{ Free triiodothyronine (FT3) } \\
\hline & Before & Change & $\%$ Change & Before & Change & $\%$ Change & Before & Change & $\%$ Change \\
\hline \multicolumn{10}{|c|}{ Caraccio et al. (23) } \\
\hline T4 & - & - & - & 11.6 & 2.8 & 24 & 4.8 & 0.3 & 6 \\
\hline Placebo & - & - & - & 12.7 & 0.2 & 2 & 4.8 & 0.1 & 2 \\
\hline \multicolumn{10}{|c|}{ Monzani et al. (30) } \\
\hline $\mathrm{T} 4$ & - & - & - & 11.3 & 2.6 & 23 & 4.8 & 0.1 & 2 \\
\hline Placebo & - & - & - & 10.9 & -0.1 & -1 & 4.6 & 0 & 0 \\
\hline \multicolumn{10}{|c|}{ Teixeira et al. (27) } \\
\hline $\mathrm{T} 4$ & 8.0 & -5.88 & -74 & 12.9 & 4.1 & 32 & - & - & - \\
\hline Placebo & 8.4 & -3.5 & -42 & 12.9 & 2 & 16 & - & - & - \\
\hline \multicolumn{10}{|c|}{ Teixeira et al. (28) } \\
\hline $\mathrm{T} 4$ & 7.5 & -4.6 & -61 & 14.2 & 0 & 0 & - & - & - \\
\hline Placebo & 8.01 & -2.01 & -25 & 14.2 & 1.2 & 8 & - & - & - \\
\hline \multicolumn{10}{|c|}{ Nagasaki et al. (32) } \\
\hline $\mathrm{T} 4$ & 7.32 & -4.62 & -63 & 14.5 & 1.5 & 10 & 5.06 & 0.08 & 2 \\
\hline \multirow[t]{3}{*}{ Placebo } & 7.25 & -0.24 & -3 & 14 & 0.8 & 6 & 4.92 & 0.2 & 4 \\
\hline & \multicolumn{3}{|c|}{ Total cholesterol } & \multicolumn{3}{|c|}{ LDL cholesterol } & \multicolumn{3}{|c|}{ HDL cholesterol } \\
\hline & Before & Change & $\%$ Change & Before & Change & $\%$ Change & Before & Change & $\%$ Change \\
\hline \multicolumn{10}{|c|}{$\overline{\text { Caraccio et al. (23) }}$} \\
\hline $\mathrm{T} 4$ & 5.5 & -0.5 & -9 & 3.6 & -0.5 & -14 & 1.5 & -0.1 & -7 \\
\hline Placebo & 5.3 & 0 & 0 & 3.3 & 0.1 & 3 & 1.5 & 0 & 0 \\
\hline \multicolumn{10}{|c|}{ Monzani et al. (30) } \\
\hline $\mathrm{T} 4$ & 5.54 & -0.58 & -10 & 3.59 & -0.51 & -14 & 1.46 & -0.05 & -3 \\
\hline Placebo & 5.51 & 0.17 & 3 & 3.55 & 0.1 & 3 & 1.47 & 0.02 & 1 \\
\hline \multicolumn{10}{|c|}{ Teixeira et al. (27) } \\
\hline $\mathrm{T} 4$ & 5.62 & -0.52 & -9 & 3.57 & -0.51 & -14 & 1.36 & 0.06 & 4 \\
\hline Placebo & 4.83 & 0.41 & 8 & 2.94 & 0.41 & 14 & 1.43 & -0.18 & -13 \\
\hline \multicolumn{10}{|c|}{ Teixeira et al. (28) } \\
\hline T4 & 5.54 & -0.58 & -10 & 3.57 & -0.48 & -13 & 1.44 & -0.08 & -6 \\
\hline Placebo & 4.87 & 0.19 & 4 & 3.05 & 0.38 & 12 & 1.43 & -0.14 & -10 \\
\hline \multicolumn{10}{|c|}{ Nagasaki et al. (32) } \\
\hline $\mathrm{T} 4$ & 5.59 & -0.4 & -7 & 3.58 & -0.44 & -12 & 1.41 & 0 & 0 \\
\hline \multirow[t]{3}{*}{ Placebo } & 5.53 & -0.2 & -4 & 3.56 & -0.2 & -6 & 1.38 & 0.01 & 1 \\
\hline & \multicolumn{3}{|c|}{ Triglycerides } & & lipoprotei & & & olipopro & in B \\
\hline & Before & Change & $\%$ Change & Before & Change & $\%$ Change & Before & Change & $\%$ Change \\
\hline Caraccio et & & & & & & & & & \\
\hline $\mathrm{T} 4$ & 1.3 & -0.1 & -8 & 1.618 & -0.128 & -8 & 1.096 & -0.083 & -8 \\
\hline Placebo & 1.4 & -0.1 & -7 & 1.584 & 0.031 & 2 & 1.053 & 0.018 & 2 \\
\hline Monzani et & & & & & & & & & \\
\hline T4 & 1.06 & -0.07 & -7 & 1.66 & -0.14 & -8 & 1.07 & -0.09 & -8 \\
\hline Placebo & 1.07 & 0.09 & 8 & 1.65 & 0.04 & 2 & 1.17 & 0.01 & 1 \\
\hline Teixeira et & & & & & & & & & \\
\hline $\mathrm{T} 4$ & 1.21 & -0.02 & -2 & 1.376 & 0.04 & 3 & 0.966 & 0.059 & 6 \\
\hline Placebo & 1.08 & 0.31 & 29 & 1.338 & -0.034 & -3 & 0.915 & 0.009 & 1 \\
\hline Teixeira et & & & & & & & & & \\
\hline $\mathrm{T} 4$ & 1.16 & -0.07 & -6 & 1.403 & 0.093 & 7 & 0.948 & -0.041 & -4 \\
\hline Placebo & 1.11 & -0.1 & -9 & 1.407 & 0.019 & 1 & 0.889 & 0.017 & 2 \\
\hline Nagasaki e & & & & & & & & & \\
\hline $\mathrm{T} 4$ & 1.34 & 0.16 & 12 & - & - & - & - & - & - \\
\hline Placebo & 1.37 & 0.01 & 1 & - & - & - & - & - & - \\
\hline
\end{tabular}


four focused on both lipid profile and cardiac or vascular parameters $(29,30,31,32)$, two focused essentially on cardiac function and structure $(14,33)$, one accessed mainly reactive $C$ protein and homocysteine values (34), and another evaluated primarily changes in Pro-A-type and N-terminal pro-B-type natriuretic peptides (35). Two studies also assessed scores to analyse the impact of mild thyroid disease on subjective health and quality of life, and no significant changes were reported $(19,20)$.

\section{Meta-analysis}

Figure 2 shows the overall changes of responses to placebo or levothyroxine treatments in serum thyroid hormones, namely TSH, FT4, FT3, and lipid profile (total, LDL and HDL cholesterol, triglycerides and apolipoproteins $\mathrm{A}$ and $\mathrm{B})$. Table 4 shows the mean percentage change between before and post treatment for each variable analysed.

Within the active treatment, TSH values declined by $-3.91 \mathrm{IU} / \mathrm{L}$, with a $95 \%$ confidence interval (CI) of -2.62 to $-5.20 \mathrm{IU} / \mathrm{L}$, using a random effects model (Fig. 2A). Only three of the five studies considered for the meta-analysis were included in the TSH analysis, as the two studies excluded present data as interval values that could not be compared with the mean and standard deviation of the other three studies. The mean percentage change in serum TSH with levothyroxine treatment was $-66 \%$ (range of $-61 \%$ to $-74 \%$ ), compared with a mean percentage change by $-23 \%$ (range of $-3 \%$ to $-42 \%$ ) in the placebo group. Serum TSH changes were significantly different, comparing placebo and active group arms $(P<0.00001)$.

During thyroxine-based therapy, an increased in FT4 by $1.59 \mathrm{pmol} / \mathrm{L}$ with a $95 \%$ confidence interval (CI) of 0.34-2.84 pmol/L was noticed (Fig. 2C), using a random effects model. Despite the overall results favouring treatment with levothyroxine, it is possible to observe that three out of five studies crossed the baseline to favour placebo and that there is evidence of heterogeneity of the studies ( $I^{2} \geq 50 \%$ and Cochrane's $\chi^{2}$ test with $\left.P<0.10\right)$. Although statistically significant $(P=0.01)$, the studies might be too dissimilar to combine.

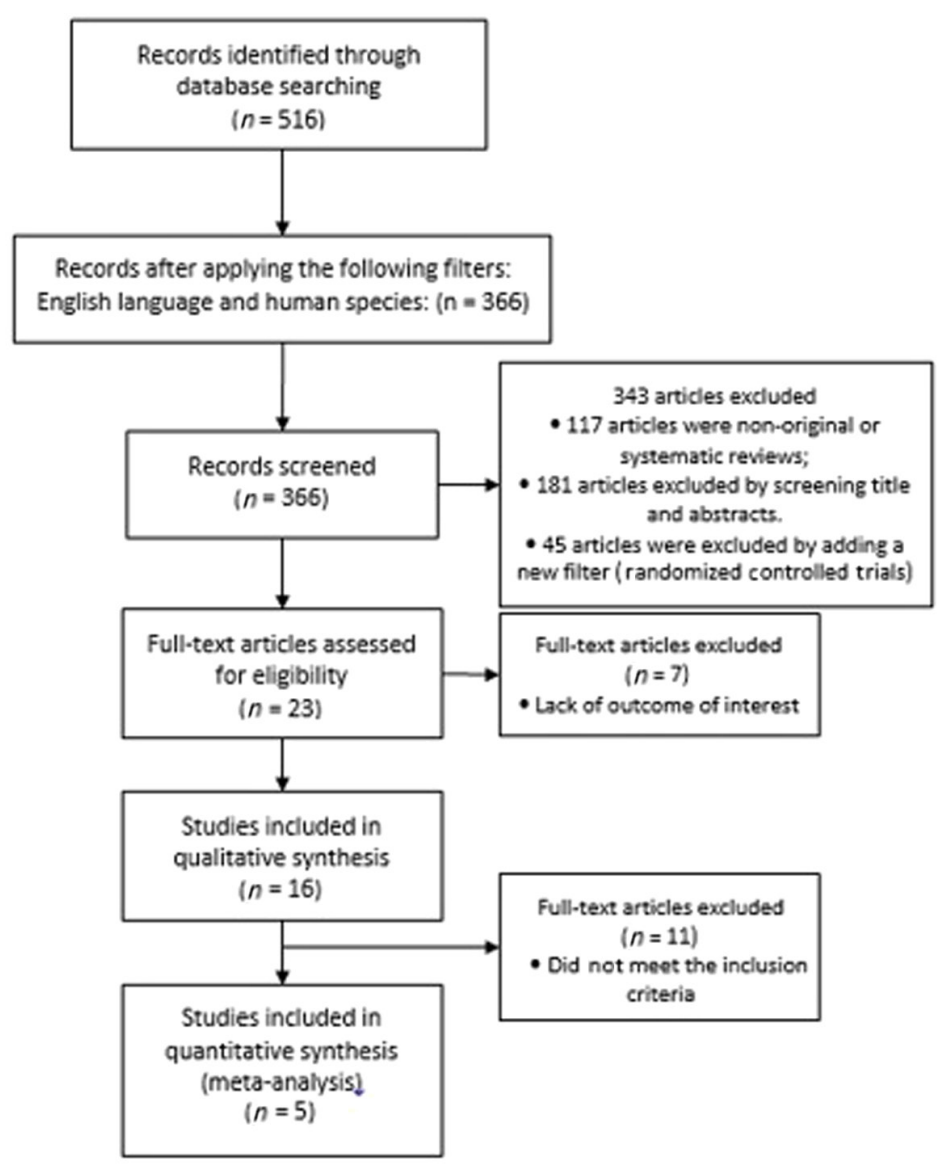

Figure 1

Flow chart of the inclusion criteria for this study.

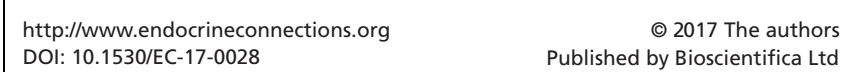
Published by Bioscientifica Ltd 

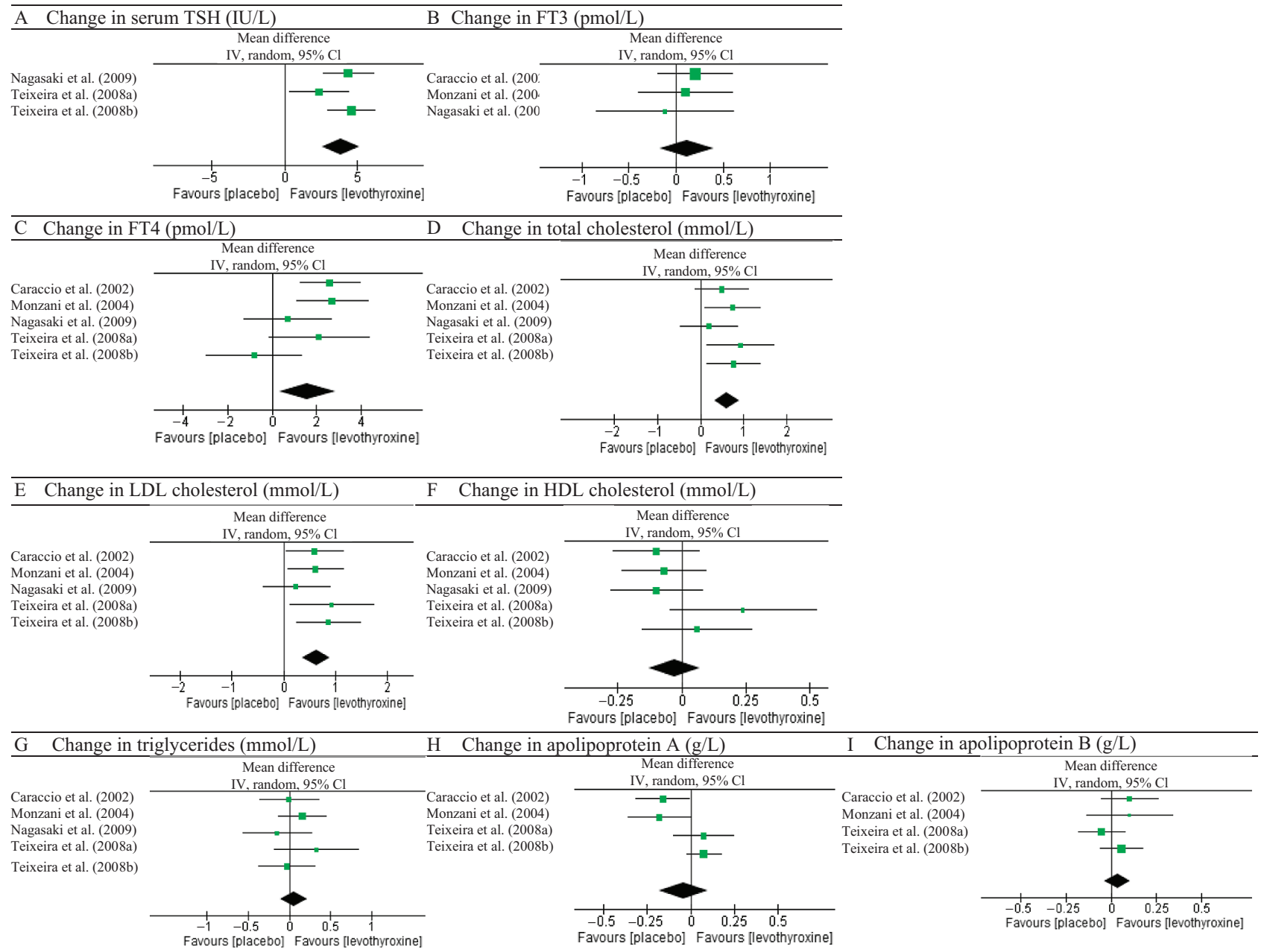

Figure 2

Raw analysis from studies. Changes in thyroid hormones and lipid parameters between levothyroxine and placebo groups.

Finally, only three studies show results regarding FT3 levels, with an increase by $0.12 \mathrm{pmol} / \mathrm{L}$ with a $95 \%$ IC of -0.17 to $0.40 \mathrm{pmol} / \mathrm{L}$ (Fig. $2 \mathrm{~B}$ ). The overall result crossed the baseline and has no significance $(P=0.42)$, although it is without heterogeneity.

After initiating the therapy, a reduction in total cholesterol was observed. In random models, serum total cholesterol decreased by $-0.62 \mathrm{mmol} / \mathrm{L}$, with a $95 \%$ CI of -0.91 to $-0.32 \mathrm{mmol} / \mathrm{L}$, equivalent to a mean percentage change of $-9 \%$ (range from $-10 \%$ to $-7 \%$ ). The overall effect of levothyroxine treatment showed a significant reduction in total cholesterol levels $(P<0.0001)$.

Regarding the LDL cholesterol, a greater decrease by $-0.62 \mathrm{mmol} / \mathrm{L}$ (with a CI between -0.90 and $-0.35 \mathrm{mmol} / \mathrm{L}$ ) was obtained with levothyroxine treatment than with control. This represented a mean percentage change of $-14 \%$ (range between $-14 \%$ and $-12 \%$ ) in serum LDL levels on the levothyroxine group, contrary to the mean percentage change of $2 \%$ (range from $-4 \%$ to $8 \%$ ) in the placebo group. These differences between the two groups were significant $(P<0.00001)$.

Levothyroxine treatment showed no significant improvement of HDL when compared with placebo $(P=0.59)$, with a mean difference of $-0.03 \mathrm{mmol} / \mathrm{L}$ (ranging from -0.13 to $0.07 \mathrm{mmol} / \mathrm{L}$ ), using a random effects model.

Using a random effects model, no significant difference of serum triglycerides between the levothyroxine and placebo group was found $(P=0.51)$. The mean difference was $-0.06 \mathrm{mmol} / \mathrm{L}$, with a $95 \%$ CI from -0.22 to $0.11 \mathrm{mmol} / \mathrm{L}$ (for heterogeneity $l^{2}=0 \%$ ).

Only four out of five studies analysed the effect of levothyroxine on serum apolipoproteins $\mathrm{A}$ and B. No significant overall effect was found for both $(P=0.57$ for apolipoprotein A, and $P=0.41$ for apolipoprotein $\mathrm{B}$ between levothyroxine and placebo treatments). Notably, significant heterogeneity was found regarding 
apolipoprotein A ( $\chi^{2}$ test with $P=0.01$ and $\left.I^{2}=73 \%\right)$, and thus the studies might be too different to support a conclusion. An overall decrease of serum apolipoprotein A by $-0.04 \mathrm{~g} / \mathrm{L}(95 \%$ CI from -0.18 to $0.10 \mathrm{~g} / \mathrm{L}$ ) and of apolipoprotein B by $-0.04 \mathrm{~g} / \mathrm{L}$ (95\% CI from -0.11 to $0.03 \mathrm{~g} / \mathrm{L}$, with heterogeneity $\chi^{2}$ test of $P=0.41$ and $I^{2}=0 \%$ ) between the two groups was shown.

\section{Discussion}

Subclinical hypothyroidism is progressively being associated with increased cardiovascular risk and poor outcomes, such as atherosclerosis and the associated cardiovascular events. This systematic review and meta-analysis of randomized placebo-controlled trials assesses the different impact of levothyroxine vs placebo treatment. We assessed parameters frequently used on a daily basis, such as lipid profile (including total, LDL and HDL cholesterol, and triglycerides). Moreover, additional selection criteria were chosen to better reflect a population with normal cardiovascular risk and no previous/current treatments, which could interfere with the analysed parameters. Thus, the main purpose of this review and meta-analysis was to assess whether managing subclinical hypothyroidism is of clinical value, based on lipid profile as cardiovascular risk parameters.

Throughout the meta-analysis we found a statistically significant decrease on total and LDL cholesterol with levothyroxine treatment compared with the placebo group, but not on other lipid parameters. It should be emphasized that decline in total and LDL cholesterol induced by levothyroxine therapy, although modest (9\% and $14 \%$ ), could be significant in terms of the reduction in the incidence of coronary artery disease (36), as LDL cholesterol is strongly associated with increasing rates of atherosclerosis, cardiovascular disease, stroke and other vascular complications (37). The Helsinki Heart Study has shown that, in men, a reduction of only $7 \%$ in LDL cholesterol levels is associated with a $15 \%$ reduction in the incidence of coronary heart disease (38), although comparable data are not available for premenopausal women. Our study showed a decrease in LDL cholesterol twice compared to that reported in Helsinki Heart Study ( $14 \%$ vs $7 \%$ ), which could be translated to further cardiovascular risk reduction. Helfand and Redfern (39) showed that a $0.6 \mathrm{mmol} / \mathrm{L}$ reduction in serum total cholesterol levels in a 60-year-old woman, with no other risk factors, would reduce the 10-year risk of ischaemic heart disease from $10 \%$ to $9 \%$. Hence, 1000 women would need to be treated to prevent one new case of ischaemic heart disease per year.

Overall, concerning the changes in lipid profile, two studies showed no changes in serum cholesterol or triglycerides levels within the active levothyroxine treatment group $(29,32)$. On the contrary, others reported statistically and clinically significant reductions on total and LDL cholesterol within the levothyroxine treatment group $(22,23,25,26,27,28,30,31)$. These reductions were significant when comparing to the placebo group in some studies $(21,22,23,24,25,27)$. While Mikhail and coworkers (26) also obtained a significant decrease in triglycerides levels, Meier and coworkers (22) and Iqbal and coworkers (25) obtained a significant reduction on apolipoprotein B-100 levels within levothyroxine group. Additionally, it was hypothesized that, since the apolipoprotein B-100/ LDL cholesterol ratio did not change, levothyroxine treatment resulted in smaller and more atherogenic LDL particles, instead of a depletion of LDL cholesterol (22). Additional sub-analyses were performed in order to study the particularities of levothyroxine treatment. A greater lipid-lowering effect of levothyroxine treatment was found in patients with: elevated pre-treatment total and LDL cholesterol $(\geq 6.2 \mathrm{mmol} / \mathrm{L}$ and $\geq 4.0 \mathrm{mmol} / \mathrm{L}$, respectively) and apolipoprotein B levels (>1.35 g/L) (22); serum TSH levels between 0.2 and 2.0 IU/L after 1 year of levothyroxine medication (25), or greater than $8 \mathrm{IU} / \mathrm{L}$ after 6 months of levothyroxine treatment (28); and positive antiperoxidase antibodies, body mass index equal to or greater than $25 \mathrm{~kg} / \mathrm{m}^{2}$, and the presence of menopause in women (28).

The analysed studies also showed the impact of subclinical hypothyroidism management on other predictors of cardiovascular events, such as carotid artery intima-media thickness (IMT), brachial artery flow mediated dilation (FMD), brachial-ankle pulse wave velocity (baPWV), C-reactive protein (CRP) and circulating natriuretic peptides levels (atrial natriuretic peptide (ANP) and brain natriuretic peptide (BNP)). As a significant reduction of the mean IMT was found when compared to the placebo group (directly related to the decrease of both total cholesterol and TSH), the authors could conclude that not only early carotid artery wall alterations are present in subclinical hypothyroidism, but also lipid infiltration of arterial wall may be the responsible mechanism (30). On the other hand, after three months of treatment, an increase in FMD was observed (31), which could be translated into a reduction in cardiovascular morbidity and mortality (40). BaPWV, a marker of arterial stiffness (41), was found to be significant reduced after 5 months of levothyroxine

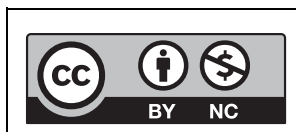

This work is licensed under a Creative Commons Attribution-NonCommercial 4.0 International License. 
treatment, despite the fact that the final values were still higher than euthyroid controls (32). Regarding CRP levels, there is a relative risk factor for cardiovascular diseases when levels are more than $3 \mathrm{mg} / \mathrm{L}$. While some authors did not find significant changes (32), others found that CRP, but not homocysteine values, showed no significant improvement with levothyroxine treatment (34), despite being affected by subclinical hypothyroidism. Thus, they are not determinants to start levothyroxine replacement therapy. Finally, levothyroxine treatment showed no effect on circulating natriuretic peptides levels (35).

Monzani and coworkers (15) and Martins and coworkers (33) focused primarily on cardiac systolic and diastolic function in subclinical hypothyroidism. Both demonstrated that subclinical hypothyroidism is related with overall impairment of both left ventricular diastolic and systolic function, which can be fully reversible with levothyroxine treatment, although it may require a longer period of treatment. Other authors found no changes in myocardial contractility (assessed by the pulse wave arrival time $\left(\mathrm{QK}_{\mathrm{D}}\right.$ interval) or the ratio between the preejection period with left ventricular ejection time (PEP/ LVET)) on a group of 33 participants with subclinical hypothyroidism among other medical problems, such as hypertension, angina and diabetes, or/and had previous thyroid treatment (29). However, in a subgroup of patients with the highest PEP/LVET ratio, a significant change occurred on the levothyroxine group (29).

Among sixteen studies, positive correlations, most likely causal, were found between serum TSH and total and LDL cholesterol levels $(23,25,30)$. This suggests that increases in total and LDL cholesterol in subclinical hypothyroidism are, to an extent, related to increased TSH levels, and these predict the degree of levothyroxine treatment response. Other positive correlations were found between: serum TSH and total cholesterol, triglycerides and apolipoprotein B levels (27); reduction in total cholesterol levels and increasing FT4 levels (31); diastolic blood pressure, apolipoprotein B to A1 ratio and serum LDL cholesterol (31); homocysteine and FT4 (34); proANP and NT-pro-BNP levels and FT4 (35); IMT and age, LDL cholesterol, triglyceride and apolipoprotein B (30); FMD and FT4 levels (40); and between baPWV and age, baseline pulse pressure (41).

Similar systematic studies had also assessed the impact of levothyroxine treatment on subclinical hypothyroidism. Danese et al. (42) conducted a literature review and analysis of prospective studies that evaluated the effect of levothyroxine treatment on serum cholesterol levels in patients with mild thyroid failure, including other studies besides randomized controlled trials. Also unlike our study, they estimate an upper TSH limit of $20 \mathrm{IU} / \mathrm{L}$. With this study, the authors could conclude that there was an important, although modest (4.3\%) reduction in total cholesterol levels with levothyroxine treatment. On the other hand, Villar et al. (43) searched the Cochrane Library, MEDLINE, EMBASE and LILACS for all randomized controlled trials comparing thyroid hormone replacement with placebo or no treatment in adults with subclinical hypothyroidism, unlike our study that only compares thyroid hormone replacement with placebo. They could also notice that within six studies that assessed serum lipids, there was a trend for reduction in some parameters following levothyroxine replacement, as some echocardiographic parameters improved after levothyroxine replacement therapy, like myocardial relaxation, as indicated by a significant prolongation of the isovolumic relaxation time as well as diastolic dysfunction.

\section{Limitations}

This study may have a language bias, as only Englishwritten reports were included. On the other hand, since only placebo-controlled randomized control trials were included, this systematic review provides a stronger evidence-based perspective about specific changes with levothyroxine treatment. However, only a reduced number of participants were included in the meta-analysis, which may mislead significant changes with levothyroxine treatment. Secondly, the population reviewed may have critical dissimilarities. Although only adults were included, the age range was too high (eighteen to over sixty years) and, as the prevalence of subclinical hypothyroidism increases with age as do other cardiovascular risk factors, the results may not be truly associated with subclinical hypothyroidism and its respective treatment. On the other hand, some patients had previous thyroid diseases or interventions that could interfere with the results observed. Others show positive thyroid antibodies, and these, associated with a familiar story as well, could show more impact on the treatment.

\section{Conclusion}

Subclinical hypothyroidism is associated with increased cardiovascular risk, and our meta-analysis and systematic http://www.endocrineconnections.org
DOI: $10.1530 /$ EC-17-0028
() 2017 The authors Published by Bioscientifica Ltd
This work is licensed under a Creative Commons Attribution-NonCommercial 4.0 International License. 
review indicates that $\mathrm{SCH}$ could benefit from thyroid hormones replacement, especially regarding total and LDL cholesterol reduction and overall left cardiac function. As the cost-effectiveness of the screening for mild thyroid dysfunction has already shown to be a favourable strategy (12), early treatment could yield improvements in lipid profile, cardiac structure and function, and could prevent progression to overt hypothyroidism.

Recently, some clinical trials have been carried out. Through International Clinical Trials Registry Platforms, we can understand that at least 9 new randomized placebo-controlled trials are underway. An example is the TRUST study, a new research project from five European universities investigating current treatment practices for people who suffer from a mildly underactive thyroid gland. This project is studying the multi-modal effects of thyroid hormone replacement for 3000 untreated older ( $\geq 65$ years old) adults with subclinical hypothyroidism, and is still currently recruiting patients.

We can conclude that subclinical hypothyroidism is a rising topic all over the world. It is being recognized greatly as a potential cardiovascular risk factor that could interfere with overall morbidity and mortality, and early evidence shows improvement with treatment. Therefore, it is essential that new insights be created to guide clinical practice within the overall population.

\section{Declaration of interest}

The authors declare that there is no conflict of interest that could be perceived as prejudicing the impartiality of the research reported.

\section{Funding}

This review did not receive any specific grant from any funding agency in the public, commercial or not-for-profit sector.

\section{References}

1 Hollowell JG, Staehling NW, Flanders WD, Hannon WH, Gunter EW, Spencer CA \& Braverman LE. Serum TSH, T(4), and thyroid antibodies in the United States population (1988 to 1994): National Health and Nutrition Examination Survey (NHANES III). Journal of Clinical Endocrinology and Metabolism 200287 489-499. (doi:10.1210/ jcem.87.2.8182)

2 Bemben DA, Hamm RM, Morgan L, Winn P, Davis A \& Barton E. Thyroid disease in the elderly. Part 2. Predictability of subclinical hypothyroidism. Journal of Family Practice 199438 583-588.

3 Bell RJ, Rivera-Woll L, Davison SL, Topliss DJ, Donath S \& Davis SR. Well-being, health-related quality of life and cardiovascular disease risk profile in women with subclinical thyroid disease - a communitybased study. Clinical Endocrinology 200766 548-556.

4 Duntas LH. Thyroid disease and lipids. Thyroid 200212 287-293. (doi:10.1089/10507250252949405)
5 Cappola AR \& Ladenson PW. Hypothyroidism and atherosclerosis. Journal of Clinical Endocrinology and Metabolism 200388 2438-2444. (doi:10.1210/jc.2003-030398)

6 Liu D, Jiang F, Shan Z, Wang B, Wang J, Lai Y, Chen Y, Li M, Liu H, Li C, et al. A cross-sectional survey of relationship between serum TSH level and blood pressure. Journal of Human Hypertension 201024 134-138. (doi:10.1038/jhh.2009.44)

7 Fox CS, Pencina MJ, D’Agostino RB, Murabito JM, Seely EW, Pearce EN \& Vasan RS. Relations of thyroid function to body weight: cross-sectional and longitudinal observations in a community-based sample. Archives of Internal Medicine 2008168 587-592. (doi:10.1001/ archinte.168.6.587)

8 Maratou E, Hadjidakis DJ, Kollias A, Tsegka K, Peppa M, Alevizaki M, Mitrou P, Lambadiari V, Boutati E, Nikzas D, et al. Studies of insulin resistance in patients with clinical and subclinical hypothyroidism. European Journal of Endocrinology 2009160 785-790. (doi:10.1530/EJE08-0797)

9 Biondi B \& Cooper DS. The clinical significance of subclinical thyroid dysfunction. Endocrine Reviews 200829 76-131. (doi:10.1210/er.20060043)

10 Rodondi N, den Elzen WP, Bauer DC, Cappola AR, Razvi S, Walsh JP \& Gussekloo J. Subclinical hypothyroidism and the risk of coronary heart disease and mortality. JAMA 2010304 1365-1374. (doi:10.1001/ jama.2010.1361)

11 Selmer C, Olesen JB, Hansen ML, von Kappelgaard LM, Madsen JC, Hansen PR, Pedersen OD, Faber J, Torp-Pedersen C \& Gislason GH. Subclinical and overt thyroid dysfunction and risk of all-cause mortality and cardiovascular events: a large population study. Journal of Clinical Endocrinology and Metabolism 201499 2372-2382. (doi:10.1210/jc.2013-4184)

12 Danese MD, Powe NR, Sawin CT \& Ladenson PW. Screening for mild thyroid failure at the periodic health examination: a decision and cost-effectiveness analysis. JAMA 1996276 285-292. (doi:10.1001/ jama.1996.03540040029029)

13 Garber JR, Cobin RH, Gharib H, Hennessey JV, Klein I, Mechanick JI, Pessah-Pollack R, Singer PA \& Woeber KA. Clinical practice guidelines for hypothyroidism in adults: cosponsored by the American Association of Clinical Endocrinologists and the American Thyroid Association. Endocrine Practice 201218 988-1028. (doi:10.4158/EP12280.GL)

14 Jonklaas J, Bianco AC, Bauer AJ, Burman KD, Cappola AR, Celi FS, Cooper DS, Kim BW, Peeters RP \& Rosenthal MS. Guidelines for the treatment of hypothyroidism: prepared by the American Thyroid Association Task Force on Thyroid Hormone Replacement. Thyroid 201424 1670-1751. (doi:10.1089/thy.2014.0028)

15 Monzani F, Di Bello V, Caraccio N, Bertini A, Giorgi D, Giusti C $\&$ Ferrannini E. Effect of levothyroxine on cardiac function and structure in subclinical hypothyroidism: a double blind, placebocontrolled study. Journal of Clinical Endocrinology and Metabolism 2001 86 1110-1115. (doi:10.1210/jcem.86.3.7291)

16 Rugge B, Balshem H \& Sehgal R. Comparative effectiveness reviews. In Screening and Treatment of Subclinical Hypothyroidism or Hyperthyroidism. Ed OE-bP Center. Rockville, MD, USA: Agency for Healthcare Research and Quality (US), 2011.

17 Mak ACY, Pullinger CR, Tang LF, Wong JS, Deo RC, Schwarz J-M, Gugliucci A, Movsesyan I, Ishida BY, Chu C, et al. Effects of the absence of apolipoprotein $\mathrm{E}$ on lipoproteins, neurocognitive function, and retinal function. JAMA 201471 1228-1236. (doi:10.1001/ jamaneurol.2014.2011)

18 Higgins JP, Thompson SG, Deeks JJ \& Altman DG. Measuring inconsistency in meta-analyses. British Medical Journal 2003327 557-560. (doi:10.1136/bmj.327.7414.557)

19 Borenstein M, Hedges LV, Higgins JPT \& Rothstein HR 2009 Effect sizes based on means. In Introduction to Meta-Analysis, pp 21-32. Hoboken, NJ, USA: John Wiley \& Sons, Ltd.

20 DerSimonian R \& Laird N. Meta-analysis in clinical trials. Controlled Clinical Trials 19867 177-188. (doi:10.1016/0197-2456(86)90046-2)

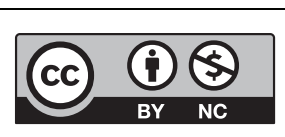

This work is licensed under a Creative Commons Attribution-NonCommercial 4.0 International License. 
21 Jaeschke R, Guyatt G, Gerstein H, Patterson C, Molloy W, Cook D, Harper S, Griffith L \& Carbotte R. Does treatment with L-thyroxine influence health status in middle-aged and older adults with subclinical hypothyroidism? Journal of General Internal Medicine 1996 11 744-749. (doi:10.1007/BF02598988)

22 Meier C, Staub JJ, Roth CB, Guglielmetti M, Kunz M, Miserez AR, Drewe J, Huber P, Herzog R \& Muller B. TSH-controlled L-thyroxine therapy reduces cholesterol levels and clinical symptoms in subclinical hypothyroidism: a double blind, placebo-controlled trial (Basel Thyroid Study). Journal of Clinical Endocrinology and Metabolism 200186 4860-4866. (doi:10.1210/jcem.86.10.7973)

23 Caraccio N, Ferrannini E \& Monzani F. Lipoprotein profile in subclinical hypothyroidism: response to levothyroxine replacement, a randomized placebo-controlled study. Journal of Clinical Endocrinology and Metabolism 200287 1533-1538. (doi:10.1210/jcem.87.4.8378)

24 Kong WM, Sheikh MH, Lumb PJ, Naoumova RP, Freedman DB, Crook M, Dore CJ \& Finer N. A 6-month randomized trial of thyroxine treatment in women with mild subclinical hypothyroidism. American Journal of Medicine 2002112 348-354. (doi:10.1016/S00029343(02)01022-7)

25 Iqbal A, Jorde R \& Figenschau Y. Serum lipid levels in relation to serum thyroid-stimulating hormone and the effect of thyroxine treatment on serum lipid levels in subjects with subclinical hypothyroidism: the Tromso study. Journal of Internal Medicine 2006 260 53-61. (doi:10.1111/j.1365-2796.2006.01652.x)

26 Mikhail GS, Alshammari SM, Alenezi MY, Mansour M \& Khalil NA. Increased atherogenic low-density lipoprotein cholesterol in untreated subclinical hypothyroidism. Endocrine Practice 200814 570-575. (doi:10.4158/EP.14.5.570)

27 Teixeira PF, Reuters VS, Ferreira MM, Almeida CP, Reis FA, Buescu A, Costa AJ \& Vaisman M. Lipid profile in different degrees of hypothyroidism and effects of levothyroxine replacement in mild thyroid failure. Translational Research 2008 151 224-231. (doi:10.1016/j.trsl.2007.12.006)

28 Teixeira PF, Reuters VS, Ferreira MM, Almeida CP, Reis FA, Melo BA Buescu A, Costa AJ \& Vaisman M. Treatment of subclinical hypothyroidism reduces atherogenic lipid levels in a placebocontrolled double-blind clinical trial. Hormone and Metabolic Research 200840 50-55. (doi:10.1055/s-2007-993216)

29 Cooper DS, Halpern R, Wood LC, Levin AA \& Ridgway EC. L-Thyroxine therapy in subclinical hypothyroidism. A double-blind, placebo-controlled trial. Annals of Internal Medicine 1984101 18-24. (doi:10.7326/0003-4819-101-1-18)

30 Monzani F, Caraccio N, Kozakowa M, Dardano A, Vittone F, Virdis A, Taddei S, Palombo C \& Ferrannini E. Effect of levothyroxine replacement on lipid profile and intima-media thickness in subclinical hypothyroidism: a double-blind, placebo-controlled study. Journal of Clinical Endocrinology and Metabolism 200489 2099-2106. (doi:10.1210/jc.2003-031669)

31 Razvi S, Ingoe L, Keeka G, Oates C, McMillan C \& Weaver JU. The beneficial effect of L-thyroxine on cardiovascular risk factors, endothelial function, and quality of life in subclinical hypothyroidism: randomized, crossover trial. Journal of Clinical
Endocrinology and Metabolism 200792 1715-1723. (doi:10.1210/ jc.2006-1869)

32 Nagasaki T, Inaba M, Yamada S, Shirakawa K, Nagata Y, Kumeda Y, Hiura Y, Tahara H, Ishimura E \& Nishizawa Y. Decrease of brachialankle pulse wave velocity in female subclinical hypothyroid patients during normalization of thyroid function: a double-blind, placebocontrolled study. European Journal of Endocrinology 2009160 409-415. (doi:10.1530/EJE-08-0742)

33 Martins RM, Fonseca RH, Duarte MM, Reuters VS, Ferreira MM, Almeida C, Buescu A, Teixeira Pde F \& Vaisman M. Impact of subclinical hypothyroidism treatment in systolic and diastolic cardiac function. Arquivos Brasileiros de Endocrinologia and Metabologia 2011 55 460-467. (doi:10.1590/S0004-27302011000700005)

34 Christ-Crain M, Meier C, Guglielmetti M, Huber PR, Riesen W, Staub JJ \& Muller B. Elevated C-reactive protein and homocysteine values: cardiovascular risk factors in hypothyroidism? A crosssectional and a double-blind, placebo-controlled trial. Atherosclerosis 2003166 379-386. (doi:10.1016/S0021-9150(02)00372-6)

35 Christ-Crain M, Morgenthaler NG, Meier C, Muller C, Nussbaumer C, Bergmann A, Staub JJ \& Muller B. Pro-A-type and N-terminal pro-Btype natriuretic peptides in different thyroid function states. Swiss Medical Weekly 2005135 549-554.

36 Law MR, Wald NJ \& Thompson SG. By how much and how quickly does reduction in serum cholesterol concentration lower risk of ischaemic heart disease? British Medical Journal 1994308 367-372. (doi:10.1136/bmj.308.6925.367)

37 Glagov S, Weisenberg E, Zarins CK, Stankunavicius R \& Kolettis GJ. Compensatory enlargement of human atherosclerotic coronary arteries. New England Journal of Medicine 1987316 1371-1375. (doi:10.1056/NEJM198705283162204)

38 Manninen V, Elo MO, Frick MH, Haapa K, Heinonen OP, Heinsalmi P, Helo P, Huttunen JK, Kaitaniemi P, Koskinen P, et al. Lipid alterations and decline in the incidence of coronary heart disease in the Helsinki Heart study. JAMA 1988260 641-651. (doi:10.1001/ jama.1988.03410050061031)

39 Helfand M \& Redfern CC. Clinical guideline, part 2. Screening for thyroid disease: an update. American College of Physicians. Annals of Internal Medicine 1998129 144-158. (doi:10.7326/0003-4819-129-2199807150-00020)

40 Bonetti PO, Lerman LO \& Lerman A. Endothelial dysfunction: a marker of atherosclerotic risk. Arteriosclerosis, Thrombosis, and Vascular Biology 200323 168-175. (doi:10.1161/01.ATV.0000051384.43104.FC)

41 Yamashina A, Tomiyama H, Arai T, Hirose K, Koji Y, Hirayama Y, Yamamoto Y \& Hori S. Brachial-ankle pulse wave velocity as a marker of atherosclerotic vascular damage and cardiovascular risk. Hypertension Research 200326 615-622. (doi:10.1291/hypres.26.615)

42 Danese M, Landerson P, Meinert CL \& Powe N. Effect of thyroxine on serum lipoproteins in patients with mild failure: a quantitative review of the literature. Journal of Clinical Endocrinology and Metabolism 2000 85 2993-3001. (doi:10.1210/jcem.85.9.6841)

43 Villar HC, Saconato H, Valente O \& Atallah AN. Thyroid hormone replacement for subclinical hypothyroidism. Cochrane Database of Systematic Reviews 20073 CD003419. (doi:10.1002/14651858. CD003419.pub2)

Received in final form 14 February 2017

Accepted 1 March 2017

Accepted Preprint published online 1 March 2017 http://www.endocrineconnections.org DOI: 10.1530/EC-17-0028
() 2017 The authors Published by Bioscientifica Ltd

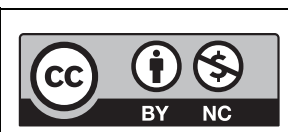

This work is licensed under a Creative Commons Attribution-NonCommercial 4.0 International License. 